\title{
PENERAPAN FUNGSI DATA MERGE PADA ADOBE PHOTOSHOP
}

\author{
Jenisa Felisa \\ Sekolah Tinggi Manajemen Informatika dan Komputer LIKMI \\ Jl. Ir. H. Juanda no 96 Bandung \\ jenisafelisa@gmail.com
}

\begin{abstract}
ABSTRAK
Penerapan Data Merge sebagai fasilitas untuk menghubungkan sebuah file data dengan template dokumen sudah sering dijumpai pada parangkat lunak pengolah dokumen, hanya saja untuk data berupa citra sangat terbatas dilakukan untuk aplikasi pengolah dokumen. Adobe Photoshop sebagai aplikasi yang paling umum digunakan untuk pengolahan citra memiliki fasilitas untuk melakukan Data Merge yang dapat digunakan untuk dokumen berupa teks dan citra. Dengan adanya fasilitas Data Merge dalam photoshop, pengguna dapat membuat template desain yang berisi beberapa variabel data yang akan diisi dengan data yang sudah disimpan dalam format ekstensi CSV atau TXT. Fungsi tentunya akan mempercepat proses penggunaan sebuah desain yang dipakai berkali-kali atau dicetak dalam jumlah besar.
\end{abstract}

Kata kunci : Data Merge, Variabel, Template, Adobe Photoshop, ekstensi CSV atau TXT.

\section{PENDAHULUAN}

Data Merge atau penggabungan data merupakan sebuah fungsi yang digunakan untuk menggabungkan sebuah file data sel dengan sebuah template dokumen dengan tujuan agar template tersebut dapat digunakan berkali-kali. Data sel yang digunakan terdiri dari satu atau lebih variabel yang nantinya akan dihubungkan dengan variabel yang ada pada template dokumen. Fungsi Data Merge paling umum ditemukan dalam fasilitas Mail Merge pada perangkat lunak Microsoft Word atau perangkat lunak pengolah dokumen lainnya, hanya saja untuk data berupa citra sangat terbatas dilakukan untuk aplikasi pengolah dokumen.

Data Merge untuk file citra dapat digunakan dalam perangkat lunak Adobe Photoshop yang tentunya merupakan salah satu perangkat lunak yang paling populer digunakan dikalangan profesional maupun orang awan untuk keperluan pengolahan gambar. Adobe Photoshop dapat membaca file data dengan format ekstensi A Comma Separated Values (.csv) atau Text (.txt). Proses penyusunan File Data dengan ekstensi CSV dan TXT bersifat sederhana karena data dapat dimasukkan hanya dengan pemisahan tanda baca koma saja sehingga mudah untuk disusun, dan dimodifikasi oleh pengguna.

Secara garis besar, penerapan fungsi Data Merge dalam Adobe Photoshop dibagi menjadi 2 proses yaitu penyusunan file data, dan pendefinisian variabel data dalam template desain.

\section{PENYUSUNAN FILE DATA}

Dalam menyusun file data sel, pengguna dapat menggunakan perangkat lunak pengolah teks sederhana seperti notepad atau notepad++, karena photoshop cenderung lebih pemilih dalam membaca file data, sehingga penyusunan dengan perangkat lunak sel 
yang lebih rumit / advanced seperti Microsoft Excel perlu adanya proses penghapusan format tanda baca yang tidak diperlukan. sederhana.

Berikut merupakan contoh pengetikan file data dengan perangkat lunak teks

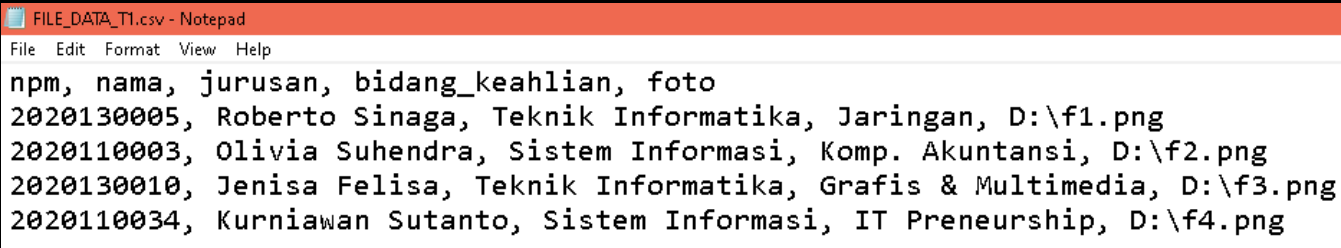

Gambar 1. Contoh Pengetikan File Data

Ketentuan penulisan yang perlu diperhatikan adalah :

a. Baris pertama diisi dengan nama-nama variabel yang akan digunakan, pisahkan nama variabel dengan tanca baca koma

b. Baris kedua dan seterusnya adalah isi dari data masing-masing variabel, pisahkan nama variabel dengan tanca baca koma

c. Untuk penulisan data citra (image), isi dengan alamat lengkap tempat citra disimpan

d. Baris baru akan menandakan isi data baru

e. Jika data di copy-paste dari perangkat lunak pengolah sel seperti Ms. Exce, pastikan tidak ada penambahan tanda baca lain selain sebuah koma, jika ada lebih dari satu koma, pengguna harus menghapus tanda baca yang tidak diperlukan

f. Simpan file data hanya dalam ekstensi .csv atau .txt

\section{PENDEFINISIAN VARIABEL DAN DATA SET}

Setelah menyimpan file data yang akan dipakai, pengguna dapat membuka desain template yang akan diterapkan fungsi Data Merge dalam Adobe Photoshop. Berikut contoh desain template kartu mahasiswa yang akan diisikan data seperti pada Gambar 1.

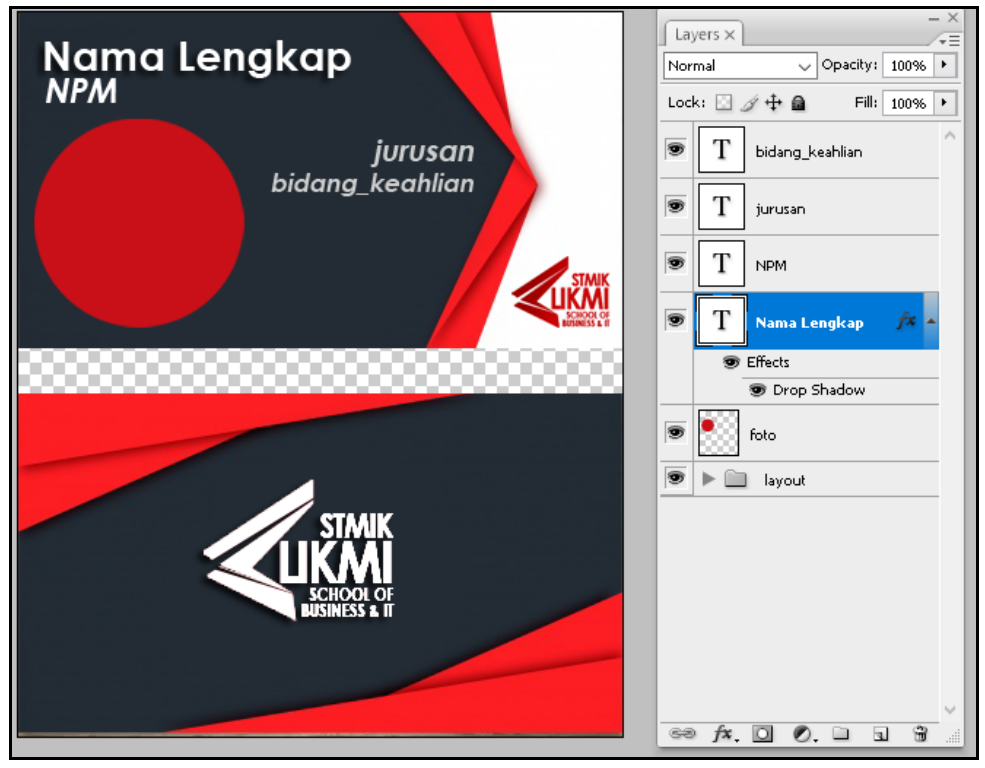

Gambar 2. Contoh Desain Template 
Berikut merupakan langkah pendefinisian variabel dan data set :

a. Buka desain template yang akan digunakan, pastikan variabel yang akan diisi dengan file data telah terpisah layernya, untuk data teks dapat dibuat dengan text tool, sedangkan untuk data citra dapat menggunakan tool apapun yang dapat menghasilkan sebuah shape yang akan menjadi bingkai dari citra yang akan di-merge. Perhatikan panel layer pada gambar 2 untuk masing-masing variabel

b. Klik menu Image $\rightarrow$ Variables $\rightarrow$ Defines, sehingga akan muncul kotak dialog Variable.

1) Pada bagian layer, pilih layer-layer yang akan dijadikan variabel, tandai bagian "text replacement" atau "pixel replacement" (biarkan visbility nya)

2) Isi bagian "name" dengan nama variabel yang sama dengan yang ada pada file data (lihat kecocokan gambar 1 dan gambar 2 contohnya)

3) Untuk "pixel replacement", pilih method yang akan digunakan ; fit (memasukkan semua citra kedalam bingkai shape), fill (mengambil sebagian dari citra untuk dicocokan dengan bingkai shape), As It (citra dibiarkan sebagaimana ukuran asalnya), conform (menekan citra sampai ukurannya sesuai dengan ukuran bingkai shape).

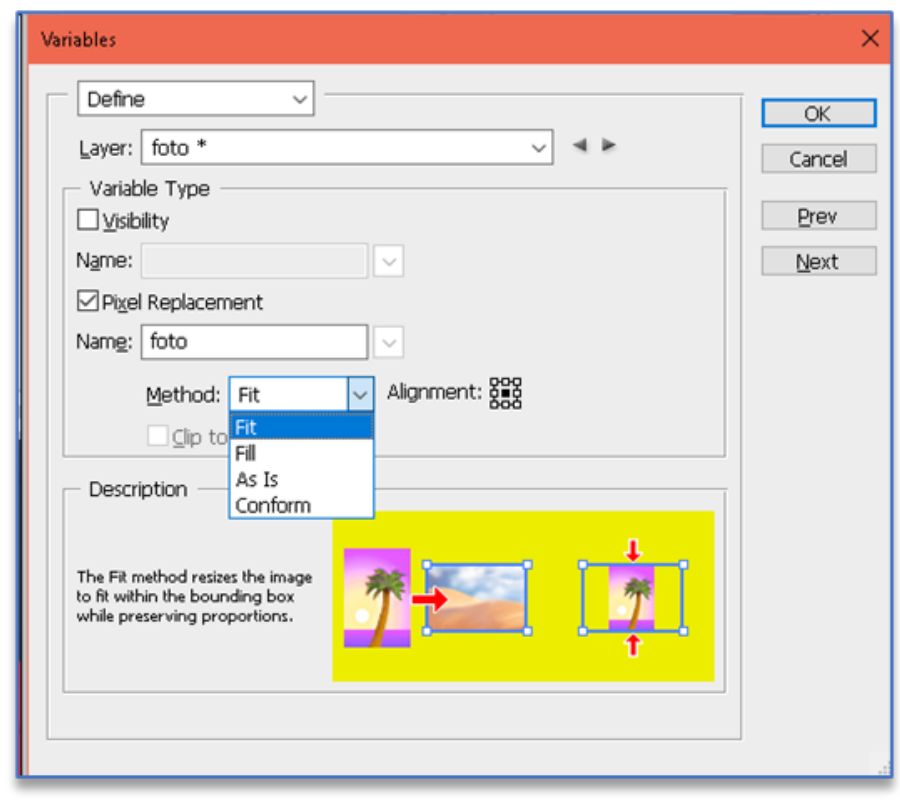

Gambar 3. Kotak Dialog Variables

c. Klik Image $\rightarrow$ Variables $\rightarrow$ Data Sets, sehingga akan muncul kotak dialog Data Sets

d. Pada kotak dialog Data Sets, Klik tombol "Import...", sehingga muncul kotak dialog Import Data Sets, lalu klik tombol "Select File...", pilih file data yang akan digunakan (perhatikan fiter file, pilih antara CSV atau TXT), lalu klik "OK” pada kotak diaog Import Data Sets.

e. Kembali ke kotak dialog Data Sets, tandai bagian "Preview" sehingga pengguna dapat melihat hasil Data Merge yang dilakukan, panah kanan dan kiri (disebelah kanan bagian Data Set) untuk melihat data satu persatu, jika ingin menggunakan data yang ada untuk keperluan selanjutnya, pengguna dapat menekan tombol "Apply". 

pada Adobe Photoshop

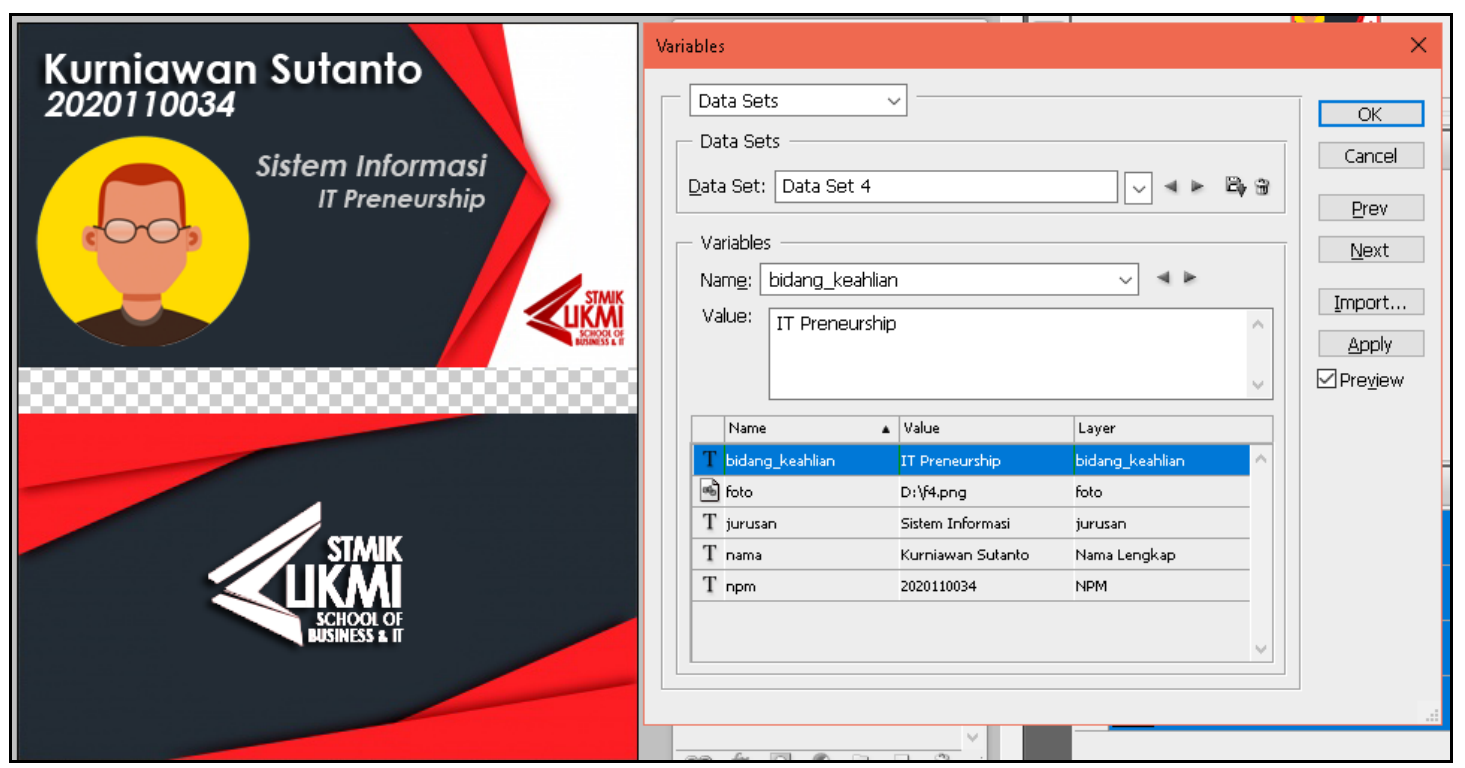

Gambar 4. Hasil Preview Data Merge

\section{KESIMPULAN}

Perangkat lunak Adobe Photoshop memiliki fasilitas Data Merge dimana sebuah desain dapat digabungkan isinya dengan file data yang berisi variabel-variabel yang bisa berulangkali di modifikasi dan digunakan sehingga dapat mempercepat proses desain dengan menggunakan data yang banyak.

\section{DAFTAR PUSTAKA}

[1] Lynch, Richard, 2004, "The Hidden Power of Photoshop CS : Advenced Technique for Smarter, Faster Image Processing”, SYBEX Inc, London.

[2] Scott, Geoff and Jeffrey Tranberry, 2013, "Power, Speed \& Automation with Adobe Photoshop", Focal Press Taylor \& Francis Group, New York and London. 